\title{
Aurora Kinase Inhibitor
}

National Cancer Institute

\section{Source}

National Cancer Institute. Aurora Kinase Inhibitor. NCI Thesaurus. Code C62556.

Any substance that inhibits Aurora kinase, a serine/threonine kinase that is involved in

mitotic spindle morphology, centrosome function, chromatid separation, and cytokinesis.

Aurora kinases are overexpressed in a variety of human cancers. 